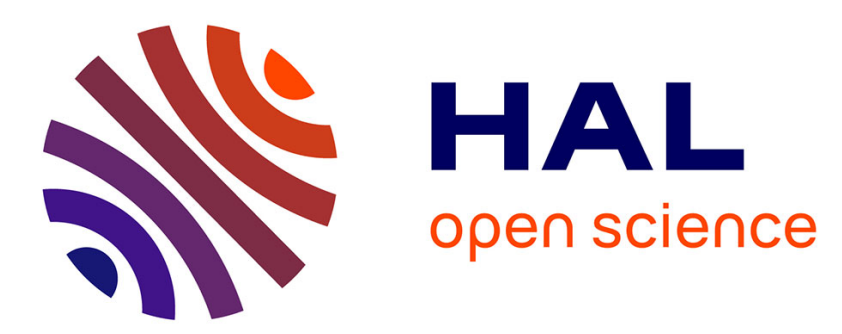

\title{
AH-Substructures in Strong Refined Neutrosophic Modules
}

\author{
Mohammad Abobala, Ahmad Hatip
}

\section{To cite this version:}

Mohammad Abobala, Ahmad Hatip. AH-Substructures in Strong Refined Neutrosophic Modules. International Journal of Neutrosophic Science, 2020, 9, pp.110 - 116. 10.5281/zenodo.3960802 . hal02915737

\section{HAL Id: hal-02915737 \\ https://hal.science/hal-02915737}

Submitted on 20 Aug 2020

HAL is a multi-disciplinary open access archive for the deposit and dissemination of scientific research documents, whether they are published or not. The documents may come from teaching and research institutions in France or abroad, or from public or private research centers.
L'archive ouverte pluridisciplinaire HAL, est destinée au dépôt et à la diffusion de documents scientifiques de niveau recherche, publiés ou non, émanant des établissements d'enseignement et de recherche français ou étrangers, des laboratoires publics ou privés. 


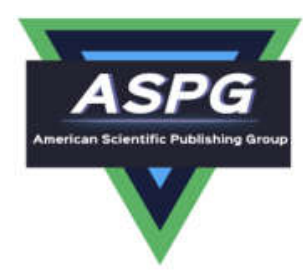

\title{
AH-Substructures in Strong Refined Neutrosophic Modules
}

\author{
${ }^{1}$ Mohammad Abobala, ${ }^{2}$ Ahmad Hatip \\ ${ }^{1}$ Faculty of science, Tishreen University, Syria \\ e-mail: mohammadabobala777@gmail.com \\ ${ }^{2}$ Department of Mathematics, Gaziantep University, Turkey \\ e-mail: Kollnaar5@.gmail.com
}

\begin{abstract}
The objective of this paper is to define and study the concepts of strong AH-submodule, and AH-homomorphism in a refined neutrosophic module. Also, this work describes the algebraic structure of all AH-endomorphisms defined over a refined neutrosophic module.
\end{abstract}

Keywords: Refined neutrosophic module, Strong AH-submodule, AH-homomorphism

\section{Introduction}

A neutrosophic set is a powerful general formal framework which generalizes the concept of the classic set, fuzzy set [13], interval valued fuzzy set [12], intuitionistic fuzzy set [9] etc. A neutrosophic set $A$ defined on a universe $U . x=x(T, I, F) \in A$ with $T, I$ and $F$ being the real standard or non-standard subsets of $] 0^{-}, 1^{+}[. T$ is the degree of truth membership function in the set $\mathrm{A}, \mathrm{I}$ is the indeterminacy-membership function in the set $A$ and $F$ is the falsity-membership function in the set $A$. Agboola introduced the concept of refined neutrosophic algebraic structures and studied refined neutrosophic groups in particular [6]. Adeleke et al. in [7,8] studied refined neutrosophic rings and refined neutrosophic subrings and presented their fundamental properties. Recently, Hatip et al. studied refined neutrosophic modules and refined neutrosophic homomorphisms modules and presented their basic properties [10,11]. Abobala et al. in [1,2] studied some special substructures of refined neutrosophic rings. Also in [3], Abobala et al. studied classical homomorphisms between refined neutrosophic rings and neutrosophic rings and presented their basic properties. Abobala and Alhamido studied AH-substructures in neutrosophic modules and AH-subspaces in neutrosophic vector spaces [4,5].

The present paper is devoted to the study of AH-strong refined neutrosophic modules. Also, the strong AHhomomorphism modules will be established. 


\section{Preliminaries}

In this section, we present the basic definitions that are useful in this research.

Definition 2.1: [10] Let $(M,+,$.$) be any R-module over aneutrosophic ring R(I)$, The triple $(M(I),+, \cdot)$ is called a strong neutrosophic R-module over a neutrosophic ring $R(I)$, generated by $M$ and $I$.

Definition 2.2: [6] Let $\left(X\left(I_{1}, I_{2}\right),+, \cdot\right)$ be any refined neutrosophic algebraic structure where + and $\cdot$ are ordinary addition and multiplication respectively. $I_{1}$ and $I_{2}$ are the split components of the indeterminacy factor $I$ that is $I=\alpha I_{1}+\beta I_{2}$ with $\alpha, \beta \in R$ or $C$. Also, $I_{1}$ and $I_{2}$ are taken to have the properties $I_{1}^{2}=I_{1}, I_{2}^{2}=I_{2}$ and $I_{1} I_{2}=I_{2} I_{1}=I_{1}$.

For any two elements, we define

1) $x+y=\left(a, b I_{1}, c I_{2}\right)+\left(d, e I_{1}, f I_{2}\right)=\left(a+d,(b+e) I_{1},(c+f) I_{2}\right)$

2) $x \cdot y=\left(a, b I_{1}, c I_{2}\right) \cdot\left(d, e I_{1}, f I_{2}\right)=\left(\begin{array}{l}a d,(a e+b d+b e+b f+c e) I_{1} \text {, } \\ (a f+c d+c f) I_{2}\end{array}\right)$

Definition 2.3: [10] Let $(M,+,$.$) be any R-module over a refined neutrosophic \operatorname{ring} R\left(I_{1}, I_{2}\right)$, The triple $\left(M\left(I_{1}, I_{2}\right),+, \cdot\right)$ is called a strong refined neutrosophic R-module over a refined neutrosophic ring $R\left(I_{1}, I_{2}\right)$, generated by $M, I_{1}$ and $I_{2}$.

Definition 2.4: Let $M(I)$ be a strongneutrosophicR-module, the set $S=P+Q I=\{x+y I: x \in P, y \in Q\}$ where $P$ and $Q$ are submodules of $M$ is called an AH-submodule of $M(I)$ and If $P=Q$ then $S$ is called an AHS-submodule of $M(I)$.

\section{Main discussion}

Definition 3.1:

Let $M\left(I_{1}, I_{2}\right)$ be a strong refined neutrosophic module over the refined neutrosophic ring $R\left(I_{1}, I_{2}\right), P, Q, S$ be three submodules of $\mathrm{M}$. The set $\mathrm{N}=\left(P, Q I_{1}, S I_{2}\right)=\left\{\left(a, b I_{1}, c I_{2}\right) ; a \in P, b \in Q, c \in S\right\}$ is called a strong AH-submodule of the strong refined neutrosophic module $M\left(I_{1}, I_{2}\right)$.

If $\mathrm{P}=\mathrm{Q}=\mathrm{S}$, we call $\mathrm{N}$ a strong AHS-submodule.

\section{Theorem 3.2:}

Let $M\left(I_{1}, I_{2}\right)$ be a strong refined neutrosophic module over the refined neutrosophic ring $R\left(I_{1}, I_{2}\right)$,

$\mathrm{N}=\left(P, P I_{1}, P I_{2}\right)$ be a strong AHS-submodule. Then $\mathrm{N}$ is a submodule by classical meaning. 


\section{Proof:}

The proof is similar to that of theorem 3.4 in [13].

An AH-submodule is not supposed to be a submodule of $M\left(I_{1}, I_{2}\right)$ in general. See the following example.

\section{Example 3.3:}

Let $M=Z_{6}$ be a module over the ring of integers $Z$, the corresponding refined neutrosophic module is

$M\left(I_{1}, I_{2}\right)=\left\{\left(a, b I_{1}, c I_{2}\right) ; a, b, c \in M\right\}$ over the refined neutrosophic ring $Z\left(I_{1}, I_{2}\right)$, we have $P=\{0,3\}, Q=\{0,2,4\}$ as two submodules of $\mathrm{M}$.

$N=\left(P, Q I_{1}, P I_{2}\right)$ is a strong AH-submodule of $M\left(I_{1}, I_{2}\right), x=\left(2,3 I_{1}, 0\right) \in N, r=\left(1, I_{1}, I_{2}\right) \in Z\left(I_{1}, I_{2}\right)$

$r \cdot x=\left(2,[2+3+3+3+0] I_{1},[2+0+0] I_{2}\right)=\left(2,5 I_{1}, 2 I_{2}\right)$, which is not in $\mathrm{N}$, thus $\mathrm{N}$ is not a submodule.

Theorem 3.4: Let $M\left(I_{1}, I_{2}\right)$ be a strong refinedneutrosophic R-module over a refined neutrosophic ring $R\left(I_{1}, I_{2}\right)$ and let $\left\{N_{n}\right\}_{n \in \lambda}$ be a family of a strong AH-submoduleof $M\left(I_{1}, I_{2}\right)$. Then $\cap\left\{N_{n}\right\}_{n \in \lambda}$ is a strong AH-submodule of $M\left(I_{1}, I_{2}\right)$.

Proof: Clearly $\cap\left\{N_{n}\right\}_{n \in \lambda} \neq \varnothing, \forall n \in \lambda$ let we have $x=\left(a, b I_{1}, c I_{2}\right), y\left(d, e I_{1}, f I_{2}\right) \in \cap\left\{N_{n}\right\}_{n \in \lambda}$ for $a, b, c, d, e, f$ belong to $P, Q, S, T, V, K$ respectively where $P, Q, S, T, V, K$ are asubmodules of $M$ and let be $\quad \alpha=\left(p, q I_{1}, r I_{2}\right) \in R\left(I_{1}, I_{2}\right)$. Then $\quad x+y, \alpha x \in \cap\left\{N_{n}\right\}_{n \in \lambda}$. Since, for $\forall n \in \lambda, x+y \in \cap\left\{N_{n}\right\}_{n \in \lambda}$ and $\alpha x \in \cap\left\{N_{n}\right\}_{n \in \lambda}$ Hence $\cap\left\{N_{n}\right\}_{n \in \lambda}$ is a strong AH-submoduleof $M\left(I_{1}, I_{2}\right)$.

Remark 3.5: Let $M\left(I_{1}, I_{2}\right)$ be a strong refinedneutrosophic R-module over a refinedneutrosophic ring $R\left(I_{1}, I_{2}\right)$ and let $N_{1}$ and $N_{2}$ be two distinct strong AH-submoduleof $M\left(I_{1}, I_{2}\right)$. Generally, $N_{1} \cup N_{2}$ is not a strongAH-submoduleof $M\left(I_{1}, I_{2}\right)$.

However, if $N_{1} \subseteq N_{2}$ or $N_{1} \supseteq N_{2}$ then $N_{1} \cup N_{2}$ is a AH-submoduleof $M\left(I_{1}, I_{2}\right)$.

\section{Definition 3.6:}

Let $M, W$ be two modules over the ring $\mathrm{R}, M\left(I_{1}, I_{2}\right)$ and $W\left(I_{1}, I_{2}\right)$ be the corresponding strong refined neutrosophic modules over the refined neutrosophic ring $R\left(I_{1}, I_{2}\right)$. Let $f, g, h: M \rightarrow W$ be three homomorphisms, then 
$[f, g, h]: M\left(I_{1}, I_{2}\right) \rightarrow W\left(I_{1}, \mathrm{I}_{2}\right) ;[f, g, h]\left(a, b I_{1}, c I_{2}\right)=\left(f(a), g(b) I_{1}, h(c) I_{2}\right)$ is called a strong AH-homomorphism. If $f=g=h$, we get the strong AHS-homomorphism.

\section{Definition 3.7:}

Let $M\left(I_{1}, I_{2}\right), W\left(I_{1}, I_{2}\right)$ be two strong refined neutrosophic modules over the refined neutrosophic $\operatorname{ring} R\left(I_{1}, I_{2}\right)$, $[f, g, h]: M\left(I_{1}, I_{2}\right) \rightarrow W\left(I_{1}, I_{2}\right)$ be a strong AH-homomorphism, we define

(a) $A H-\operatorname{Ker}[f, g, h]=\left(\operatorname{Ker}(f), \operatorname{Ker}(g) I_{1}, \operatorname{Ker}(h) I_{2}\right)=\left\{\left(a, b I_{1}, c I_{2}\right) ; a \in \operatorname{Ker}(f), b \in \operatorname{Ker}(g), c \in \operatorname{Ker}(h)\right\}$.

(b) $A H-\operatorname{Im}[f, g, h]=\left(\operatorname{Im}(f), \operatorname{Im}(g) I_{1}, \operatorname{Im}(h) I_{2}\right)$.

\section{Theorem 3.8:}

Let $M\left(I_{1}, I_{2}\right), W\left(I_{1}, I_{2}\right)$ be two strong refined neutrosophic modules over the refined neutrosophic $\operatorname{ring} R\left(I_{1}, I_{2}\right)$, $[f, g, h]: M\left(I_{1}, I_{2}\right) \rightarrow W\left(I_{1}, I_{2}\right)$ be a strong AH-homomorphism.

(a) If $\mathrm{N}=\left(P, Q I_{1}, S I_{2}\right)$ is a strong AH-submodule of $M\left(I_{1}, I_{2}\right)$, then $[f, g, h](N)$ is a strong AH-submodule of $W\left(I_{1}, I_{2}\right)$.

(b) $[f, g, h]$ is a classical module homomorphism.

(c) $A H-\operatorname{Ker}[f, g, h]$ is a strong AH-submodule of $M\left(I_{1}, I_{2}\right)$.

(d) $A H-\operatorname{Im}[f, g, h]$ is a strong AH-submodule of $W\left(I_{1}, I_{2}\right)$.

\section{Proof:}

(a) Since $f(P), g(Q), h(S)$ are submodules of $\mathrm{N}$, we find that $[f, g, h](N)=\left(f(P), g(Q) I_{1}, h(S) I_{2}\right)$ is a strong AHsubmodule of $W\left(I_{1}, I_{2}\right)$.

(b) Let $m=\left(x, y I_{1}, z I_{2}\right), n=\left(a, b I_{1}, c I_{2}\right)$ be two arbitrary elements in $M\left(I_{1}, I_{2}\right), r=\left(t, u I_{1}, v I_{2}\right)$ be any element in $R\left(I_{1}, I_{2}\right)$,

$m+n=\left(x+a,[y+b] I_{1},[z+c] I_{2}\right), r \cdot m=\left(t x,[x u+y t+y u+y v+z u] I_{1},[x v+z t+z v] I_{2}\right)$,

$[f, g, h](m+n)=\left(f(x+a), g([y+b]) I_{1}, h([z+c]) I_{2}\right)=\left(f(x), g(y) I_{1}, h(z) I_{2}\right)+\left(f(a), g(b) I_{1}, h(c) I_{2}\right)=$ $[f, g, h](m)+[f, g, h](n)$.

$[f, g, h](r . m)=\left(f(t x), g([x u+y t+y u+y v+z u]) I_{1}, h([x v+z t+z v]) I_{2}\right)=$

$\left(t, u I_{1}, v I_{2}\right) .\left(f(x), g(y) I_{1}, h(z) I_{2}\right)=r .[f, g, h](m)$. Thus $[f, g, h]$ is a classical homomorphism.

(c) Since $\operatorname{Ker}(f), \operatorname{Ker}(g), \operatorname{Ker}(h)$ are submodules of M, then $A H-\operatorname{Ker}[f, g, h]=\left(\operatorname{Ker}(f), \operatorname{Ker}(g) I_{1}, \operatorname{Ker}(h) I_{2}\right)$ as a strong AH-submodule of $M\left(I_{1}, I_{2}\right)$.

(d) Since $\operatorname{Im}(f), \operatorname{Im}(g), \operatorname{Im}(h)$ are submodules of $\mathrm{W}$, we get $A H-\operatorname{Im}[f, g, h]=\left(\operatorname{Im}(f), \operatorname{Im}(g) I_{1}, \operatorname{Im}(h) I_{2}\right)$ as a strong AH-submodule of $W\left(I_{1}, I_{2}\right)$.

\section{Example 3.9:}

DOI: $10.5281 /$ zenodo.3960802 
(a) Let $M=R^{2}, W=R$ be two modules over the $\operatorname{ring} R$,

$f: M \rightarrow W ; f(x, y)=2 x, g: M \rightarrow W ; g(x, y)=3 y, h: M \rightarrow W ; h(x, y)=x+y$ are three homomorphisms.

(b) $[f, g, h]: M\left(I_{1}, I_{2}\right) \rightarrow W\left(I_{1}, I_{2}\right) ;[f, g, h]\left((x, y),(z, t) I_{1},(s, m) I_{2}\right)=\left(f(x, y), g(z, t) I_{1}, h(s, m) I_{2}\right)=$

$\left(2 x, 3 t I_{1},[s+m] I_{2}\right)$ is a strong AH-homomorphism, where $x, y, z, t, s, m \in R$.

(c) $P=\{(0, x) ; x \in R\}, Q=\{(x, 0) ; x \in R\}$ are two submodules of $\mathrm{M}$,

$N=\left(P, P I_{1}, Q I_{2}\right)=\left\{\left((0, x),(0, y) I_{1},(z, 0) I_{2} ; x, y, z \in R\right\}\right.$ is a strong AH-submodule of $M\left(I_{1}, I_{2}\right)$.

(d) $f(P)=\{0\}, g(P)=\{3 y ; y \in R\}=R, h(Q)=\{z ; z \in R\}=R$,

$[f, g, h](N)=\left(f(P), g(P) I_{1}, h(Q) I_{2}\right)=\left(0, R I_{1}, R I_{2}\right)=\left\{\left(0, x I_{1}, y I_{2}\right) ; x, y \in R\right\}$ is a strong AH-submodule of $W\left(I_{1}, I_{2}\right)$.

(e) $\operatorname{Ker}(f)=\{(0, x) ; x \in R\}, \operatorname{Ker}(g)=\{(x, 0) ; x \in R\}, \operatorname{Ker}(h)=\{(y,-y) ; y \in R\}$,

$\left.A H-\operatorname{Ker}[f, g, h]=\left(\operatorname{ker}(f), \operatorname{Ker}(g) I_{1}, \operatorname{Ker}(h) I_{2}\right)=\left\{(0, x),(y, 0) I_{1},(z,-z) I_{2}\right) ; x, y, z \in R\right\}$

\section{Remark 3.10:}

We denote to the set of all strong AH-homomorphisms from a strong refined neutrosophic module $M\left(I_{1}, I_{2}\right)$ to itself by $A H-E N D\left(M\left(I_{1}, I_{2}\right)\right)$.

\section{Definition 3.11:}

Let $M\left(I_{1}, I_{2}\right)$ be a strong refined neutrosophic module over the refined neutrosophic ring $R\left(I_{1}, I_{2}\right)$,

$A H-\operatorname{END}\left(M\left(I_{1}, I_{2}\right)\right)$ be the set of all strong AH-endomorphisms, we define operations on $A H-\operatorname{END}\left(M\left(I_{1}, I_{2}\right)\right)$ as follows:

Let $f_{i}, g_{i} ; i \in\{0,1,2\}$ be any homomorphisms from $M$ to itself, we define

Addition: $\left[f_{0}, f_{1}, f_{2}\right]+\left[g_{0}, g_{1}, g_{2}\right]=\left[f_{0}+g_{0}, f_{1}+g_{1}, f_{2}+g_{2}\right]$.

Multiplication by a scalar, if $r=\left(r_{0}, r_{1} I_{1}, r_{2} I_{2}\right)$ is any element in $R\left(I_{1}, I_{2}\right)$, then

$r=\left(r_{0}, r_{1} I_{1}, r_{2} I_{2}\right) \cdot\left[f_{0}, f_{1}, f_{2}\right]=$

$\left[r_{0} f_{0},\left(r_{0} f_{1}+r_{1} f_{0}+r_{1} f_{1}+r_{1} f_{2}+r_{2} f_{1}\right),\left(r_{0} f_{2}+r_{2} f_{2}+r_{2} f_{0}\right)\right]$.

Multiplication: $\left[f_{0}, f_{1}, f_{2}\right] o\left[g_{0}, g_{1}, g_{2}\right]=$

$\left[f_{0} \circ g_{0}, f_{0} \circ g_{1}+f_{1} o g_{0}+f_{1} o g_{1}+f_{1} o g_{2}+f_{2} o g_{1}, f_{0} o g_{2}+f_{2} o g_{0}+f_{2} o g_{2}\right]$.

\section{Theorem 3.12:}

$\left(A H-\operatorname{END}\left(M\left(I_{1}, I_{2}\right)\right),+, o\right)$ is a refined neutrosophic ring.

\section{Proof:}


Since $L=\{f: M \rightarrow M ; f$ is a homomorphism $\}$ is a ring with respect to addition and multiplication, then $L\left(I_{1}, I_{2}\right)$ is a refined neutrosophic ring as a result of the definition of neutrosophic rings. It is easy to see that $L\left(I_{1}, I_{2}\right)=A H-$ $\operatorname{END}\left(M\left(I_{1}, I_{2}\right)\right.$, thus we get the desired proof.

\section{Theorem 3.13:}

$\left(A H-E N D\left(M\left(I_{1}, I_{2}\right)\right),+,.\right)$ is a refined neutrosophic module.

\section{Proof:}

Since $L=\{f: M \rightarrow M ; f$ is a homomorphism $\}$ is a module with respect to addition and multiplication by a scalar taken from the ring $\mathrm{R}$, we regard that $L\left(I_{1}, I_{2}\right)=A H-\operatorname{END}\left(M\left(I_{1}, I_{2}\right)\right.$ is a strong refined neutrosophic module over the refined neutrosophic ring $R\left(I_{1}, I_{2}\right)$ as a simple result from the definition of strong neutrosophic modules.

\section{Conclusion}

In this research, we have defined the AH- Strong refined neutrosophic modules, and established the definition of AH-homomorphisms in refined neutrosophic modules. We have proved some theories related to these issues and given some clarifying examples.

\section{Future Research Directions}

As a future work, this article can be extended to include semi AH-homomorphism in modules as well as the definition of semi refiend homomorphism in general.

Funding: "This research received no external funding"

Conflicts of Interest: "The authors declare no conflict of interest."

\section{References}

[1] Abobala, M., "On Some Special Substructures of Neutrosophic Rings and Their Properties", International Journal of Neutrosophic Science", Vol. 4 , pp. 72-81, 2020.

[2] Abobala, M., "On Some Special Substructures of Refined Neutrosophic Rings", International Journal of Neutrosophic Science, Vol. 5, pp. 59-66, 2020.

[3] Abobala, M,. "Classical Homomorphisms Between Refined Neutrosophic Rings and Neutrosophic Rings", International Journal of Neutrosophic Science, Vol. 5, pp. 72-75, 2020.

[4] Abobala, M., "AH-Subspaces in Neutrosophic Vector Spaces", International Journal of Neutrosophic Science, Vol. 6, pp. 80-86, 2020.

[5] Abobala, M., and Alhamido, R., "AH-Substructures in Neutrosophic Modules", International Journal of Neutrosophic Science, Vol. 7, pp. 79-86, 2020.

[6] Agboola, A.A.A., "On Refined Neutrosophic Algebraic Structures”, Neutrosophic Sets and Systems,Vol.10, pp. 99-101, 2015.

[7]Adeleke, E.O., Agboola, A.A.A.,and Smarandache, F., "RefinedNeutrosophicRings I",International Journal of Neutrosophic Science, Vol. 2(2), pp. 77-81, 2020. 
[8] Adeleke, E.O., Agboola, A.A.A., and Smarandache, F.,"Refined Neutrosophic Rings II",International Journal of Neutrosophic Science, Vol. 2(2), pp. 89-94, 2020

[9] Atanassov, K., "Intuitionistic Fuzzy Sets”, Fuzzy Sets and Systems, 20, pp.87-96, 1986.

[10] Olgun, N., and Khatib, A., "Neutrosophic Modules", Journal of Biostatistic and Biometric Application", Vol. 3, 2018.

[11] Olgun, N., and Hatip, A., " On Refined Neutrosophic R-Module", International Journal of Neutrosophic Science, Vol. 7, pp.87-96, 2020.

[12] Turksen, I., "Interval valued fuzzy sets based on normal forms", Fuzzy Sets and Systems, 20, pp.191-210, 1986.

[13] Zadeh, L., "Fuzzy Sets", Inform and Control, 8, pp.338-353, 1965. 